\title{
Propensão dos estudantes africanos da UFAL ao empreendedorismo
}

\section{The propensity of African students in UFAL towards entrepreneurism}

\author{
Nelsio Rodrigues de Abreu \\ Universidade Federal da Paraíba - UFPB \\ e-mail: nelsio@gmail.com
}

Helder J. L. F. Monteiro Abreu

Universidade Federal de Alagoas - UFAL

Anaximandro Zylene Casimiro Menut

Universidade Federal de Alagoas - UFAL

Recebido em 12 de março de 2012. Aprovado em 28 de setembro de 2012

Editor Responsável: Edson Roberto Scharf, Dr.

Processo de avaliação por double blind review

\begin{abstract}
Resumo
A finalidade deste artigo é analisar a propensão dos estudantes africanos ao empreendedorismo. Mensurar e avaliar o perfil empreendedor desse público é de fundamental importância, tanto científica como social, visto que permite a proposição de alternativas visando uma educação empreendedora para aqueles que são os potencias agentes de mudança quando retornarem aos seus países. Trata-se de um estudo descritivo, levado a termo com 49 estudantes africanos vinculados a UFAL por meio do Programa Estudante Convênio de Graduação - PEC-G. A abordagem metodológica é quantitativa, que tem a intenção de garantir a precisão dos resultados. Foram abordados, com a utilização de um questionário, mais de $90 \%$ da população investigada. O tratamento e a análise dos dados foram realizados com a utilização do Software SPSS - Statistical Package for the Social Sciences. Os resultados mostraram que os estudantes têm propensão ao empreendedorismo.
\end{abstract}

Palavras-Chave: Empreendedorismo, Perfil empreendedor, Estudantes africanos.

Abstract
The purpose of this paper is to analyze the propensity of African students towards entrepreneurism. Measuring and assessing the entrepreneur profile of this public is of fundamental importance, in both scientific and social terms, as it enables the proposition of alternatives with a view to an entrepreneur based education for those who are the potential change agents when they return to their countries. It is a descriptive study made with 49 African students linked to UFAL through the Student Graduation Convention Program - PEC-G. The methodological approach is quantitative so as to guarantee the correctness of the results. More than $90 \%$ of the population was researched by using a questionnaire. The treatment and analysis of the data was handled with SPSS Software - Statistical Package for the Social Sciences. The results showed that the students have a propensity towards entrepreneurism. Keywords: Entrepreneurism, Entrepreneur profile and African students.

\section{Introdução}

No que diz respeito ao desenvolvimento, a sociedade contemporânea tem 
assistido, num ritmo acelerado e crescente, as transformações sociais e tecnológicas frutos de inovação das organizações. Por trás dessas invenções, existem pessoas ou equipes com características diferenciadas, que são visionárias, que arriscam, que buscam algo diferente e que, acima de tudo empreendem (SANTOS, S., 2008).

Assim, emergindo como um campo de estudo recente, empreendedorismo tem suscitado interesse de estudiosos, de diversas áreas, que atribuem ao ser empreendedor a responsabilidade pelo desenvolvimento econômicos dos seus países. Desse modo, os estudos nesta área se voltam, na maioria das vezes, para a compreensão da origem, da educação empreendedora e, acima de tudo, para identificar e traçar um perfil do ser empreendedor.

Nesse âmbito, ao responder, no seu estudo, porque surgiram empreendedores? Lisboa (2006, p. 46) recorreu ao conceito de Bateman e Snell (1998), que asseveram "as pessoas que iniciam um negócio próprio estão buscando uma qualidade de vida melhor que poderia ter em uma grande empresa, [...] sente-se tremendamente satisfeitas em construir algo do nada, ver isso alcançar sucesso e observar o mercado adotar suas idéias e seus produtos".

Dentro dessa temática existem duas correntes. Uma postula que é possível ensinar o empreendedorismo e outra acredita que o perfil empreendedor é virtude intrínseca à personalidade do indivíduo e, portanto, não é possível ensinar o empreendedorismo. Nesse contexto, mapear esse perfil entre os estudantes africanos participantes do PEC-G, se faz necessário na medida em que os Governos Africanos são, nos seus países, os maiores empregadores, visto que, as ações da iniciativa privada, no que concerne a oferta de emprego, ainda são tímidas.

A importância desse estudo se justifica ainda pelo fato desses estudantes terem uma responsabilidade com o desen- volvimento econômico dos seus países e serem considerados os potenciais agentes de mudança ao retornarem a África.

A partir do exposto, pretende-se traçar o perfil empreendedor do público alvo de acordo com as características préselecionadas por Santos, P. (2008), a saber: busca de informação; motivação; persistência; liderança; cooperação e capacidade de planejamento.

Conforme destaca Santos, P. (2008), a relevância acadêmica, está presente na originalidade da contribuição através de um instrumento que identifica traços de personalidade empreendedorística, via uma escala que usa vinhetas para auxiliar a compreensão das perguntas, em vez de simples questões, sendo ainda, de livre utilização para escolas, centros de treinamento e principalmente em universidades e empresas. Assim no caso de estudo, com estudantes africanos, em razão dos seus países ainda ter como base econômica organizações públicas, portanto, os referidos estudantes de países africanos, buscam em locais diferentes, como o Brasil uma possibilidade do desenvolvimento e aprimoramento do conhecimento com a pretensão de se tornar empreendedor e assim, ao retorno ao seu país, contribuir de forma mais efetiva, não somente conhecimento para ter empregabilidade, mas para possuir habilidades para empreender.

Assim, considerando que alguns cursos da Universidade Federal de Alagoas ofertam a disciplina de empreendedorismo, se apresenta a seguinte questão de pesquisa: Os estudantes africanos da Universidade Federal de Alagoas, participantes do Programa Estudante Convenio de Graduação (PEC-G), têm propensão ao empreendedorismo?

O Curso de Administração da UFAL tem um foco em empreendedorismo e outros cursos da IES oferecem disciplinas e seminários sobre empreendedorismo, além da universidade ter vários grupos de 
pesquisas com a temática 'empreendedorismo' e conta também com núcleos de inovações e ações de extensões direcionadas para a inovação e para os estudantes africanos, esta pesquisa visa contribuir nesta discussão.

Para responder essa questão considerou-se como objetivo geral desse estudo analisar a propensão dos estudantes africanos a empreendedorismo. Para atingir o objetivo primário é fundamental alcançar os seguintes objetivos específicos: traçar o perfil do público alvo e analisar as características empreendedoras dos pesquisados.

Apresentam-se a partir da próxima seção, os principais conceitos referentes ao empreendedorismo e ao ser empreendedor. Esses conceitos constituem a revisão da literatura e proporcionam a sustentação teórica deste trabalho.

\section{Fundamentação teórica}

\subsection{Empreendedorismo e empreende- dor: conceitos}

Considerado com um campo de pesquisa recente a literatura concernente ao empreendedorismo é relativamente ampla e farta, mas ainda não reúne consenso entre os seus estudiosos quanto à definição do termo empreendedorismo ou empreendedor.

As definições de empreendedorismo são associadas, com frequência, a alguma "forma de inovação ou comportamento inovador gerado por um indivíduo ou um grupo, diante da percepção e da ação sobre novas oportunidades" (MAIR, 2001 apud FEUERSCHÜTTE e GODOI, 2007, p. 03).

No que tange a conceituação do termo empreendedorismo Dolabela (1999), afirma que é uma livre tradução da palavra entrepreneurship, utilizado para designar os estudos relativos ao empreendedor, seu perfil, suas origens, seu sistema de atividades e o seu universo de atuação.
Ainda segundo Dolabela (2003), os fatores motivadores do desenvolvimento do empreendedorismo estão relacionados às estruturas compostas por redes, distribuição de inteligência mais homogênea, e o processo de inovação permanente e o incentivo à criatividade de indivíduos e grupos.

Segundo Frese e Rauch (2002 apud SANTOS, P. 2008), é possível que as descrições ou características de personalidade tenham uma relevância muito importante no processo pelo qual uma pessoa decida enveredar pelo empreendedorismo e iniciar seu próprio negócio, do que para posteriormente obter êxito.

Corroborando com esse conceito, Ferreira e Matos (2003) afirmam que, o empreendedorismo é o processo de descobrir ou desenvolver uma oportunidade para então, gerar valores através da inovação.

Em Hisrich e Peters (2004, p. 29) encontra-se que "o empreendedorismo como um processo dinâmico de criar mais riqueza". Enquanto Tavares e Lima (2004) argumentam que empreendedorismo é um processo multifacetado que reconhece a mobilidade social, a cultura, a sociedade, os incentivos de mercado, as políticas públicas, o capital de risco e as variáveis psicológicas como influenciadoras no ato de empreender.

Para Robbins e Decenzo (2004, p. 35) "o empreendedorismo é um processo pelo qual individuo ou grupo de pessoas arriscam dinheiro e tempo em busca de oportunidades para criar valor e crescer pela inovação independentemente pelo recurso que controlam." Assim, a procura por descrições ou personalidades empreendedoras para promover a diferenciação entre empreendedores e nãoempreendedores tem-se se renovado, em parte devido à melhoria das técnicas metodológicas (PHELAN; ALDER, 2012).

Assim, na percepção de Soava e Macêdo (2006), empreendedorismo é um fenômeno social que traz com ele implicações de diversas naturezas seja psicológica, 
social e econômica. Na visão contemporânea de Gonçalves et al. (2006), o empreendedorismo é visto como uma ferramenta para a geração de renda, emprego e desenvolvimento da economia.

Em relação ao termo empreendedor, encontra-se na obra de Hisrich e Peters (2004) o conceito mais amplo. De acordo com esses autores, do ponto de vista econômico, um empreendedor é aquele que combina recursos, trabalho, materiais e outros ativos para tornar o seu valor maior do que antes. No aspecto Psicológico um empreendedor é uma pessoa que geralmente é impulsionada por certas forças à necessidade de obter ou conseguir algo, experimentar, realizar ou talvez escapar a autoridade de outros. A seguir apresenta um resumo das definições do ser empreendedor na visão de vários autores.

- Schumpeter (1949) apud Dornelas (2001): O empreendedor é aquele que destrói a ordem econômica existente pela introdução de novos produtos e serviços, pela criação de novas formas de organização ou pela exploração de novos recursos e materiais.

- Degen (1989) Ser empreendedor significa ter, acima de tudo, a necessidade de realizar coisas novas, pôr em prática idéias próprias, características de personalidade e comportamento que nem sempre é fácil encontrar.

- Gerber (1996): Conceitua empreendedor como um ser idealista, sonhador, cheio de energia. A sua imaginação, seguida de ação é capaz de provocar grandes transformações sobre o sistema produtivo, funcionando como um catalisador de mudanças, que resulta em crescimento econômico.

- Lopes (1999): O termo tem suas raízes na história militar francesa no século 17, descrito como entrepreneur que significa começar, no caso específico de empreendedores, começar um negócio próprio.

- Dolabela (1999): O empreendedor é feito de um conjunto de atitudes e comportamentos que o predispõem a ser criativo, a identificar a oportunidade, a saber agarrá-la. E a encontrar e gerenciar os recursos necessários para transformar a oportunidade em um negócio lucrativo.

Nuevo (2001): Disserta que ser empreendedor é descobrir oportunidades onde com freqüência outros não vêem nada e transformá-las em empresas, ou seja, encontrar e utilizar as janelas estratégicas. - Dornelas (2001): Empreendedor é aquele que detecta uma oportunidade e cria negócios para capitalizar sobre ela, assumindo riscos calculados.
- Feuerschütte e Godoi (2007): $O$ indivíduo empreendedor é tido como detentor de determinados atributos que lhe predispõem ao sucesso e à eficiência, sendo freqüentemente desafiado a enfrentar situações complexas que podem transformar-se em espaços para "empreender", ou seja, para realizar ações que expressam aqueles atributos ou características.

\subsection{Perfil empreendedor}

Para Dornelas (2001) o perfil empreendedor, em regra, é composto pelas seguintes características: São pessoas visionárias; sabem tomar decisão; são indivíduos que fazem diferença; sabem explorar ao máximo as oportunidades; são determinados e dinâmicos; são dedicadas; são otimista e apaixonados pelos que fazem; são independentes e constroem o próprio destino; são líderes e formadores de equipes; são bem relacionados; são organizados; planejam; possuem conhecimento; assumem riscos calculados e criam valor para a sociedade.

Por sua vez, Gimenez e Júnior (2002) classificam o Carland Entrepreneuship Index - CEI - como um dos mais importantes instrumentos de mensuração do perfil empreendedor aceitos academicamente e empresarialmente. Para isso, o CEI utiliza por base a personalidade e as preferências do indivíduo, no qual chegou aos seguintes perfis para o empreendedor relacionados a seus traços de personalidade: necessidade de realização, criatividade, tendência à inovação, propensão ao risco e postura estratégica.

Segundo os dados do SEBRAE (2003), alguns comportamentos que classificam um indivíduo como empreendedor, são: ser organizado; conhecer o mercado; saber tomar decisões; saber aproveitar oportunidades; ter talento; ser independente; ser otimista; liderança; saber correr riscos.

Uma realidade observada é a profusão das denominadas características empreendedoras. Um grande número de traços de personalidade de empreendedores tem sido explorado e que três entre eles se 
destacam: necessidade de realização, lócus de controle e gestão de riscos (SMITHHUNTER; KAPP; YONKERS, 2003; SCHMITT-RODERMUND, 2004).

Paiva Jr. et al. (2003) levaram a termo uma pesquisa em que as competências associadas aos comportamentos de dirigentes de perfil empreendedor encontradas foram: competências de oportunidade, relacionamento, conceituais, administrativas, estratégicas, comprometimento e competências de equilíbrio trabalho/vida pessoal.

Destarte, foram consideradas, no estudo realizado por Kristiansen e Indarti (2004), como características empreendedoras a intenção empresarial, a necessidade de realização, a busca por informação, o lócus de controle e a eficácia própria.

Já no estudo realizado por Nascimento Jr. (2005) considerou que as características que formam o potencial empreendedor são: iniciativa, tenacidade, capacidade de planejamento, autoconfiança, capacidade de decisão e criatividade.

Nos estudos conduzidos, por Lima et al. (2006), com estudantes de $7^{\mathrm{a}}$ e $8^{\mathrm{a}}$ séries de escolas municipais e privadas de Maceió foram identificadas, após vasta revisão bibliográfica, as seguintes características: iniciativa, capacidade de planejamento, capacidade de correr riscos, busca de informação, criatividade, persistência, liderança e cooperação.

Portanto, diversos são os traços e características de personalidade que definem o perfil do empreendedor. O somatório dessas características é fundamental para se atingir o sucesso pessoal e profissional. De acordo com Nascimento et al. (2007, p. 02) "normalmente, quando se fala em potencial empreendedor, gera-se um conflito em relação a características empreendedoras". Esse equívoco acontece ao se pensar que os dois conceitos são iguais, mas na verdade são distintos. $\mathrm{O}$ potencial empreendedor diz respeito ao conjunto de características do empreendedor, e não às características isoladamente (NASCIMENTO et al. 2007, ).

Considerado o precursor desse tipo de análise, McClelland (1961) apud Nascimento et al. (2007) selecionou oito características comuns aos empreendedores, a saber: busca por oportunidades, busca por informação, comprometimento, persistência, capacidade de planejamento, autoconfiança, assumir riscos calculados e poder de persuasão.

Como pode ser observado, não existe um consenso sobre essa temática. $\mathrm{O}$ que na visão de Nascimento et al. (2007) coloca em pauta a confiabilidade de tais instrumentos de mensuração. Pereira e Costa (2006) argumentam que, isto ocorre devido a inúmeros fatores que podem estar relacionados ao nível de escolaridade, a religião, a cultura familiar, a experiência profissional, entre outros.

Nesta perspectiva, Dolabela (1999), afirma que mesmo sem conotações determinísticas, estas características contribuem para a identificação e a compreensão de comportamentos que podem levar o empreendedor ao sucesso.

Assim, após esta discussão teórica, surgem as hipóteses que serão testadas neste estudo sobre a propensão ao empreendedorismo dos estudantes africanos:

$H_{0}$ : Os estudantes africanos do PEC-G da UFAL não têm propensão ao empreendedorismo;

$H_{l}$ : Os estudantes africanos do PEC-G da UFAL têm propensão ao empreendedorismo.

\section{Método}

Este tópico aborda para além, da definição do tipo de pesquisa, os procedimentos metodológicos levados a termo para a consecução deste artigo. Assim, a natureza da pesquisa é descritiva. Para Triviños (2006, p. 110) "o estudo descritivo tem como foco central o desejo de conhecer, entre outros aspectos, uma comunidade, seus traços característicos, valores, crenças e opiniões. Quando se estabelecem 
relações entre variáveis, o estudo pode ser considerado como descritivo e correlacional".

A pesquisa possui um caráter quantitativo. Pesquisa quantitativa, segundo Oliveira (2004, p. 115) "significa quantificar as opiniões, dados, nas formas de coleta de informações, assim como também com o emprego de recursos e técnicas estatísticas desde as mais simples, como percentagem e média, evitando assim distorções de análise e interpretações".

O método utilizado foi o survey. "Trata-se de um método que se utiliza de um questionário estruturado aplicado a uma amostra de uma população e destinado a coletar informações específicas dos entrevistados" (MALHOTRA, 2006, p. 182).

A presente pesquisa abrangeu um universo de 52 alunos africanos do Programa Estudante Convenio de Graduação PEC-G, vinculados a UFAL (Universidade Federal de Alagoas). Desse modo, foi conduzida uma pesquisa com o universo, e resultou em uma amostra de 49 (quarenta e nove) respostas válidas, que equivale a $94,23 \%$ do publico alvo.

A coleta dos dados foi realizada no período de dois meses por meio de uma abordagem pessoal. O questionário foi resultado da adaptação de Santos, P. (2008). Optou-se pela utilização deste instrumento porque possibilita a obtenção de dados que possam responder os objetivos propostos. O instrumento é composto por 45 questões nominais e escalares.

É importante destacar que, a escolha da escala de (SANTOS, P. (2008) foi que, sua validação de conteúdo abrangeu o quanto os itens da escala cobriram os traços de personalidade do empreendedor que foram utilizados. Foi mensurada, através de julgamento de especialistas, professores de empreendedorismo, quanto ao que os itens representam o construto ao qual teoricamente estão relacionados. O julgamento foi feito através de uma pontuação indo de 1 (desnecessário), passando por 5 (útil mas não essencial) até 10 (essencial). Os itens que atingiram uma média de, no mínimo, 6, foram mantidos. A validação de construto foi realizada através de métodos estatísticos. Foi utilizada a análise fatorial. Análise fatorial, nas suas diversas formas tem sido usada para validação por pesquisadores, afirma Santos, P. (2008).

Assim, o instrumento de coleta de dados, apresenta entre seus constructos e variáveis a 'Busca de Informação', 'Motivação', 'Persistência', 'Liderança', 'Cooperação, e 'Capacidade de Planejamento', objetivando verificar estas características na amostra pesquisada.

Para a tabulação e processamento estatístico dos dados foi utilizado o Statistic Package for Social Science - SPSS. No processamento estatístico foram feitas análises univariada e análise bivariada. $\mathrm{Na}$ análise univariada foram utilizadas estatísticas associadas à distribuição de frequências como: medidas de posição central (médias, medianas e modas) para descrever o perfil dos pesquisados.

Por meio de tabulação cruzada, foram utilizados testes para avaliar a significância estatística e a intensidade da associação entre as variáveis. A significância estatística e a intensidade da associação ou dependência entre as variáveis costumam ser avaliadas pelas estatísticas $\left(\mathbf{X}^{\mathbf{2}}\right)$ Quiquadrado e V de Cramer, respectivamente.

Para responder a questão proposta nesta pesquisa, foram desenvolvidas duas hipóteses, apresentadas a seguir. $\mathrm{Na}$ concepção de Malhotra (2006, p. 74) "as hipóteses vão além das questões da pesquisa porque elas são afirmações de relações ou proposições ao invés de meras perguntas para as quais se buscam respostas. Enquanto as questões da pesquisa são interrogativas, as hipóteses são declarativas e podem ser testadas empiricamente".

$H_{0}$ : Os estudantes africanos do PEC-G da UFAL não têm propensão ao empreendedorismo; 
$H_{l}$ : Os estudantes africanos do PEC-G da UFAL têm propensão ao empreendedorismo.

Para testar a normalidade das variáveis do instrumento de pesquisa utilizou-se o teste não-paramétrico de aderência One-Sample Kolmogorov-Smirnov Test (K-S). De acordo com Malhotra (2006, p. 453) o K-S "compara a distribuição cumulativa de uma variável com uma distribuição especificada".

Rejeita-se a hipótese nula $\left(\mathrm{H}_{0}\right)$, caso o valor $p$ seja inferior ao nível de confiança desejado - compara-se o valor $p$ com $5 \%$, ou seja, se $\mathrm{p}<0,05$, rejeita-se a hipótese $\mathrm{H}_{0}$. Considerando as variáveis identificadas pelo teste $\mathrm{K}-\mathrm{S}$ de normalidade de uma amostra, assume-se a normalidade das variáveis e conclui-se, a partir de um $\mathrm{p}<0,05$ e do elevado valor de $\mathrm{K}$, que a hipótese nula $\left(\mathrm{H}_{0}\right)$ é rejeitada.

\section{Resultados e discussão}

A seguir é apresentada uma análise global de resultados. As principais informações estão divididas em dois segmentos, que são: análise univariada e análise bivariada.

\subsection{Análise Univariada}

Procede-se, nesta seção, a apresentação dos resultados das questões que possibilitam a identificação dos entrevistados através de sexo, idade, País de origem, curso, entre outros. Essas informações permitem traçar o perfil dos estudantes africanos do PEC-G.

Da análise das informações coletadas, percebe-se que a maioria dos entrevistados é do sexo feminino $(55,1 \%)$. Em relação à idade, constata-se que $46,9 \%$ estão na faixa etária de 20 a 23 anos, seguidos da categoria 24 a 27 anos (40,8\%). Registrouse igualdade $(6,1 \%)$ entre os que têm menos de 20 anos e os que estão na faixa de 27 a 30 anos. Estes dados se explicam de um lado porque a idade média para se concluir o ensino secundário nos países africanos é de 18 anos e de outro pelo timing para se conseguir uma vaga de estudos nas Instituições de Ensino Superior - IES brasileiras.

Os dados relativos ao País de origem indicam que do total dos entrevistados, $51 \%$ são nacionais da Guiné-Bissau, 40,8\% de Cabo-Verde, 4,1\% de São Tomé e Príncipe. Os estudantes de nacionalidade Angolana e Moçambicana somam 4\%.

No que diz respeito às áreas, percebe-se que $41 \%$ são das áreas de Ciências Sociais Aplicadas, $30 \%$ pertencem às áreas de Ciências da Saúde, 17\% são de Ciências Sociais e 11\% das Ciências Exatas.

As informações apresentadas a seguir favorecem a análise do comportamento dos pesquisados em relação às características empreendedoras. Assim, na tabela abaixo, procede-se a descrição das médias registradas para cada característica.

Tabela 01: Características Empreendedoras.

\begin{tabular}{c|l|c|c|c|c|c|c}
\hline \hline$\#$ & \multicolumn{1}{|c|}{ Características } & $\begin{array}{c}\text { Discordo } \\
\text { Totalmente }\end{array}$ & Discordo & Neutro & Concordo & $\begin{array}{c}\text { Concordo } \\
\text { Totalmente }\end{array}$ & Total \\
\hline \hline 1 & Busca de Informação & $0.68 \%$ & $4.08 \%$ & $26.53 \%$ & $\mathbf{5 1 . 0 2 \%}$ & $17.69 \%$ & $100.00 \%$ \\
\hline 2 & Motivação & $3.57 \%$ & $6.63 \%$ & $20.41 \%$ & $31.12 \%$ & $\mathbf{3 8 . 2 7 \%}$ & $100.00 \%$ \\
\hline 3 & Persistência & $2.81 \%$ & $4.08 \%$ & $10.97 \%$ & $\mathbf{4 7 . 9 6 \%}$ & $34.18 \%$ & $100.00 \%$ \\
\hline 4 & Liderança & $0.41 \%$ & $4.90 \%$ & $22.86 \%$ & $\mathbf{4 5 . 3 1 \%}$ & $26.53 \%$ & $100.00 \%$ \\
\hline 5 & Cooperação & $4.08 \%$ & $6.12 \%$ & $14.29 \%$ & $\mathbf{3 8 . 7 8 \%}$ & $36.73 \%$ & $100.00 \%$ \\
\hline 6 & $\begin{array}{l}\text { Capacidade de Plane- } \\
\text { jamento }\end{array}$ & $1.73 \%$ & $6.02 \%$ & $17.45 \%$ & $\mathbf{4 9 . 0 8 \%}$ & $25.71 \%$ & $100.00 \%$ \\
\hline \hline
\end{tabular}

Fonte: Dados da pesquisa 
Após a análise da Tabela 01 e utilizando a mediana como ponto de corte, verifica-se que a característica 'Busca de Informação' registrou $68,7 \%$ das respostas, quando se somado a afirmação 'concordo' e 'concordo totalmente'. Na mesma linha de raciocínio, a segunda característica, 'Motivação', alcançou 69,4\%. Para a característica 'Persistência' esse percentual aumenta para $82,1 \%$. A quarta característica registrou o menor percentual $(55,1 \%)$. Já as duas últimas características (Cooperação e Capacidade de planejamento) alcançaram 75,5\%,74,8\%, respectivamente.

De um modo geral, pode-se inferir que mais da metade da população estudada apresenta potencial empreendedor. Entretanto, chama-se a atenção para a característica 'Liderança' que registrou o menor percentual. Neste sentido, este ponto pode ser discutido em virtude que, a cultura dos estudantes de países africanos tem como maior fonte de renda, as organizações públicas governamentais, não tendo que necessariamente desenvolver tais habilidades, como se requer a iniciativa privada, por exemplo, no Brasil e outros países em desenvolvimento, e principalmente em países de primeiro mundo.

\subsection{Análise Bivariada}

Como foi abordada anteriormente, análise bivariada procura avaliar as relações entre duas variáveis. Nesse contexto, discorre-se sobre as associações entre as variáveis relacionadas às características empreendedoras e as concernentes ao perfil dos entrevistados.

Embasado por esse raciocínio, a tabela abaixo representa o cruzamento entre as questões vinculadas a dimensão sócio-demográfica (Sexo, Idade e País de origem) e uma das questões da busca de informação.

A análise dos dados da tabela a seguir ilustra que $31 \%$ das pessoas do sexo masculino concordaram totalmente que 'buscam constantemente novos conhecimentos'. Entretanto, as respostas das pessoas do sexo feminino totalizam $55 \%$.

Em relação à idade, observa-se que $31 \%$ das pessoas que se encontram na faixa etária dos 24 a 27 anos manifestaram a sua concordância total quando questionados sobre a busca de novos conhecimentos. No que concerne ao País de origem, os nacionais da Guiné-Bissau, com $51 \%$ das respostas, são os que mais procuram novos conhecimentos.

Tabela 02: Cruzamento das questões sócio-demográficas com a busca de conhecimento.

\begin{tabular}{|c|c|c|c|c|c|c|c|}
\hline \multirow{2}{*}{\multicolumn{2}{|c|}{ Descrição }} & \multicolumn{5}{|c|}{ Busco constantemente novos conhecimentos } & \multirow[b]{2}{*}{ Total } \\
\hline & & $\begin{array}{c}\text { Discordo } \\
\text { totalmente } \\
\end{array}$ & Discordo & Neutro & Concordo & $\begin{array}{c}\text { Concordo } \\
\text { Totalmente }\end{array}$ & \\
\hline \multirow{2}{*}{ Sexo } & Masculino & $0 \%$ & $0 \%$ & $0 \%$ & $14 \%$ & $31 \%$ & $45 \%$ \\
\hline & Feminino & $0 \%$ & $2 \%$ & $0 \%$ & $24 \%$ & $29 \%$ & $55 \%$ \\
\hline \multicolumn{2}{|r|}{ Total } & $0 \%$ & $2 \%$ & $0 \%$ & $39 \%$ & $59 \%$ & $100 \%$ \\
\hline \multirow{4}{*}{ Idade } & Menos de 20 anos & $0 \%$ & $0 \%$ & $0 \%$ & $2 \%$ & $4 \%$ & $6 \%$ \\
\hline & De 20 a 23 anos & $0 \%$ & $2 \%$ & $0 \%$ & $24 \%$ & $20 \%$ & $47 \%$ \\
\hline & De 24 a 27 anos & $0 \%$ & $0 \%$ & $0 \%$ & $10 \%$ & $31 \%$ & $41 \%$ \\
\hline & De 27 a 30 anos & $0 \%$ & $0 \%$ & $0 \%$ & $2 \%$ & $4 \%$ & $6 \%$ \\
\hline \multicolumn{2}{|r|}{ Total } & $0 \%$ & $2 \%$ & $0 \%$ & $39 \%$ & $59 \%$ & $100 \%$ \\
\hline \multirow{3}{*}{ Pais } & Angola & $0 \%$ & $0 \%$ & $0 \%$ & $2 \%$ & $2 \%$ & $2 \%$ \\
\hline & Cabo-Verde & $0 \%$ & $2 \%$ & $0 \%$ & $16 \%$ & $22 \%$ & $41 \%$ \\
\hline & Guiné-Bissau & $0 \%$ & $0 \%$ & $0 \%$ & $18 \%$ & $33 \%$ & $51 \%$ \\
\hline
\end{tabular}




\begin{tabular}{|c|c|c|c|c|c|c|}
\hline Moçambique & $0 \%$ & $0 \%$ & $0 \%$ & $0 \%$ & $2 \%$ & $2 \%$ \\
\hline São Tomé e Príncipe & $0 \%$ & $0 \%$ & $0 \%$ & $4 \%$ & $0 \%$ & $4 \%$ \\
\hline Total & $0 \%$ & $2 \%$ & $0 \%$ & $41 \%$ & $59 \%$ & $100 \%$ \\
\hline
\end{tabular}

Fonte: Dados da pesquisa

A Tabela 3, a seguir, demonstra o comportamento das variáveis associadas ao perfil dos entrevistados em face de uma das questões da característica 'motivação'. Assim, percebe-se que as pessoas do sexo feminino se mostram mais motivadas à criação do próprio negócio. Em relação à idade, observa-se que a segunda faixa etária (de 20 a 23 anos) se manifestou com maior entusiasmo no tocante à abertura do negócio. No que tange ao País de origem, os dados ilustram que os nascidos em Guiné-Bissau, com $51 \%$ das respostas, acreditam que um dia terão um negócio próprio.

Tabela 03: Cruzamento das questões sócio-demográficas com a intenção de ter um negócio próprio.

\begin{tabular}{|c|c|c|c|c|c|c|c|}
\hline \multirow{2}{*}{\multicolumn{2}{|c|}{ Descrição }} & \multicolumn{5}{|c|}{ Um dia Terei o meu próprio negocio } & \multirow{3}{*}{$\begin{array}{c}\text { Total } \\
45 \% \\
\end{array}$} \\
\hline & & \multirow{2}{*}{$\begin{array}{c}\begin{array}{c}\text { Discordo } \\
\text { totalmente }\end{array} \\
0 \% \\
\end{array}$} & \multirow{2}{*}{$\begin{array}{c}\text { Discordo } \\
4 \%\end{array}$} & \multirow{2}{*}{$\begin{array}{c}\text { Neutro } \\
12 \%\end{array}$} & \multirow{2}{*}{$\begin{array}{c}\text { Concordo } \\
12 \%\end{array}$} & \multirow{2}{*}{$\begin{array}{c}\begin{array}{c}\text { Concordo } \\
\text { Totalmente }\end{array} \\
16 \%\end{array}$} & \\
\hline Seyo & Masculino & & & & & & \\
\hline Sexo & Feminino & $0 \%$ & $2 \%$ & $14 \%$ & $18 \%$ & $20 \%$ & $55 \%$ \\
\hline & Total & $0 \%$ & $6 \%$ & $27 \%$ & $31 \%$ & $37 \%$ & $100 \%$ \\
\hline \multirow{4}{*}{ Idade } & Menos de 20 anos & $0 \%$ & $0 \%$ & $4 \%$ & $2 \%$ & $0 \%$ & $6 \%$ \\
\hline & De 20 a 23 anos & $0 \%$ & $2 \%$ & $12 \%$ & $14 \%$ & $18 \%$ & $47 \%$ \\
\hline & De 24 a 27 anos & $0 \%$ & $4 \%$ & $6 \%$ & $14 \%$ & $16 \%$ & $41 \%$ \\
\hline & De 27 a 30 anos & $0 \%$ & $0 \%$ & $4 \%$ & $0 \%$ & $2 \%$ & $6 \%$ \\
\hline & Total & $0 \%$ & $6 \%$ & $27 \%$ & $31 \%$ & $37 \%$ & $100 \%$ \\
\hline \multirow{5}{*}{ Pais } & Angola & $0 \%$ & $0 \%$ & $2 \%$ & $0 \%$ & $0 \%$ & $2 \%$ \\
\hline & Cabo-Verde & $0 \%$ & $0 \%$ & $12 \%$ & $16 \%$ & $12 \%$ & $41 \%$ \\
\hline & Guiné-Bissau & $0 \%$ & $6 \%$ & $10 \%$ & $12 \%$ & $22 \%$ & $51 \%$ \\
\hline & Moçambique & $0 \%$ & $0 \%$ & $2 \%$ & $0 \%$ & $0 \%$ & $2 \%$ \\
\hline & São Tomé e Príncipe & $0 \%$ & $0 \%$ & $0 \%$ & $2 \%$ & $2 \%$ & $4 \%$ \\
\hline \multicolumn{2}{|r|}{ Total } & $0 \%$ & $6 \%$ & $27 \%$ & $31 \%$ & $37 \%$ & $100 \%$ \\
\hline
\end{tabular}

Fonte: Dados da pesquisa

Tabela 04: Comportamento das questões sócio-demográficas em relação à persistência.

\begin{tabular}{|c|c|c|c|c|c|c|c|}
\hline & \multirow[b]{2}{*}{ Descrição } & \multicolumn{5}{|c|}{ Quando levo um tombo levanto e continuo } & \multirow[b]{2}{*}{ Total } \\
\hline & & $\begin{array}{l}\text { Discordo } \\
\text { totalmente }\end{array}$ & Discordo & Neutro & Concordo & $\begin{array}{c}\text { Concordo } \\
\text { Totalmente }\end{array}$ & \\
\hline \multirow{2}{*}{ Sexo } & Masculino & $2 \%$ & $2 \%$ & $2 \%$ & $14 \%$ & $24 \%$ & $45 \%$ \\
\hline & Feminino & $0 \%$ & $0 \%$ & $2 \%$ & $27 \%$ & $27 \%$ & $55 \%$ \\
\hline & Total & $2 \%$ & $2 \%$ & $4 \%$ & $41 \%$ & $51 \%$ & $100 \%$ \\
\hline \multirow{4}{*}{ Idade } & \begin{tabular}{|l|}
$\begin{array}{l}\text { Menos de } 20 \\
\text { anos }\end{array}$ \\
\end{tabular} & $0 \%$ & $0 \%$ & $0 \%$ & $2 \%$ & $4 \%$ & $6 \%$ \\
\hline & De 20 a 23 anos & $0 \%$ & $2 \%$ & $2 \%$ & $24 \%$ & $18 \%$ & $47 \%$ \\
\hline & De 24 a 27 anos & $2 \%$ & $0 \%$ & $2 \%$ & $12 \%$ & $24 \%$ & $41 \%$ \\
\hline & De 27 a 30 anos & $0 \%$ & $0 \%$ & $0 \%$ & $2 \%$ & $4 \%$ & $6 \%$ \\
\hline & Total & $2 \%$ & $2 \%$ & $4 \%$ & $41 \%$ & $51 \%$ & $100 \%$ \\
\hline \multirow{2}{*}{ País } & Angola & $0 \%$ & $0 \%$ & $0 \%$ & $0 \%$ & $2 \%$ & $2 \%$ \\
\hline & \begin{tabular}{|l|} 
Cabo-Verde \\
\end{tabular} & $0 \%$ & $0 \%$ & $0 \%$ & $14 \%$ & $27 \%$ & $41 \%$ \\
\hline
\end{tabular}




\begin{tabular}{c|c|c|c|c|c|c|c} 
Guiné-Bissau & $2 \%$ & $2 \%$ & $4 \%$ & $22 \%$ & $20 \%$ & $51 \%$ \\
\hline Moçambique & $0 \%$ & $0 \%$ & $0 \%$ & $0 \%$ & $2 \%$ & $2 \%$ \\
\cline { 1 - 7 } & $\begin{array}{l}\text { São Tomé e } \\
\text { Príncipe }\end{array}$ & $0 \%$ & $0 \%$ & $0 \%$ & $4 \%$ & $0 \%$ & $4 \%$ \\
\hline \hline
\end{tabular}

Fonte: Dados da pesquisa

A finalidade da Tabela 4 é de demonstrar os dados do comportamento dos entrevistados em relação à 'persistência', considerada uma das características de uma pessoa com perfil empreendedor. Assim, é possível observar que o gênero feminino, com $55 \%$ das respostas, declarou ser mais persistente. O que chama a atenção em relação a esse cruzamento é que $4 \%$ das pessoas do sexo masculino que discordam parcial ou totalmente 'quando inquiridos se levantam e continuam quando levam um tombo'.

Os dados da Tabela 4 ainda mostram que as pessoas na faixa etária dos 20 a 23 anos e 24 a 27 anos, com $47 \%$ e $41 \%$ das respostas, respectivamente, são os mais persistentes. Já em relação ao país de origem, destaca-se o fato de $27 \%$ dos provenientes de Cabo-Verde, em concordarem que sempre levantam e continuam quando levam um tombo. No geral, os estudantes oriundos da Guiné-Bissau totalizaram 51\% das respostas.

Na Tabela 5, constam os dados do cruzamento das questões sócio-demográ- ficas com uma das questões relacionadas à 'cooperação'. A análise da referida tabela demonstra que o gênero masculino, com $42 \%$ das respostas, se preocupa mais com a construção de boas relações que possam ser úteis. Apesar das entrevistadas registrarem $55 \%$ das respostas, $16 \%$ discordaram ou se mantiveram neutras no que tange a construção de network.

Quanto à idade, percebe-se que $24 \%$ dos entrevistados que possuem 20 a 23 anos concordaram totalmente que se preocupam com a rede de contato. Destaca-se nessa análise que $14 \%$ dos pesquisados registram a discordância ou são neutras. Esse dado é preocupante porque é a partir da construção de boas relações que se consegue, em maioria das vezes, apoio para os empreendimentos que se quer edificar. Com relação ao país de origem, os provenientes da Guiné-Bissau registraram o maior índice das respostas (52\%), sendo $50 \%$ de concordância e $2 \%$ das pessoas entrevistadas mantiveram-se neutras.

Tabela 05: Comportamento das questões sócio-demográficas em relação à cooperação.

\begin{tabular}{|c|c|c|c|c|c|c|c|}
\hline & \multirow{2}{*}{ Descrição } & \multicolumn{5}{|c|}{$\begin{array}{l}\text { Procuro estabelecer boas relações com os conhecidos, } \\
\text { amigos e pessoas que me possam ser úteis }\end{array}$} & \multirow{2}{*}{ Total } \\
\hline & & $\begin{array}{l}\text { Discordo } \\
\text { totalmente }\end{array}$ & Discordo & Neutro & Concordo & $\begin{array}{c}\text { Concordo } \\
\text { Totalmente }\end{array}$ & \\
\hline \multirow{2}{*}{ Sexo } & Masculino & $0 \%$ & $0 \%$ & $2 \%$ & $20 \%$ & $22 \%$ & $45 \%$ \\
\hline & Feminino & $2 \%$ & $2 \%$ & $8 \%$ & $16 \%$ & $24 \%$ & $55 \%$ \\
\hline & Total & $2 \%$ & $2 \%$ & $10 \%$ & $37 \%$ & $47 \%$ & $100 \%$ \\
\hline \multirow{4}{*}{ Idade } & Menos de 20 anos & $0 \%$ & $0 \%$ & $0 \%$ & $4 \%$ & $2 \%$ & $6 \%$ \\
\hline & De 20 a 23 anos & $0 \%$ & $2 \%$ & $6 \%$ & $14 \%$ & $24 \%$ & $47 \%$ \\
\hline & De 24 a 27 anos & $2 \%$ & $0 \%$ & $4 \%$ & $18 \%$ & $16 \%$ & $41 \%$ \\
\hline & De 27 a 30 anos & $0 \%$ & $0 \%$ & $0 \%$ & $0 \%$ & $4 \%$ & $6 \%$ \\
\hline & Total & $2 \%$ & $2 \%$ & $10 \%$ & $37 \%$ & $47 \%$ & $100 \%$ \\
\hline \multirow{2}{*}{ Pais } & Angola & $0 \%$ & $0 \%$ & $2 \%$ & $0 \%$ & $0 \%$ & $2 \%$ \\
\hline & Cabo-Verde & $2 \%$ & $2 \%$ & $6 \%$ & $15 \%$ & $17 \%$ & $42 \%$ \\
\hline
\end{tabular}




\begin{tabular}{|c|c|c|c|c|c|c|}
\hline Guiné-Bissau & $0 \%$ & $0 \%$ & $2 \%$ & $21 \%$ & $29 \%$ & $52 \%$ \\
\hline Moçambique & $0 \%$ & $0 \%$ & $0 \%$ & $0 \%$ & $0 \%$ & $0 \%$ \\
\hline $\begin{array}{l}\text { São Tomé e Prín- } \\
\text { cipe }\end{array}$ & $0 \%$ & $0 \%$ & $0 \%$ & $2 \%$ & $2 \%$ & $4 \%$ \\
\hline Total & $2 \%$ & $2 \%$ & $10 \%$ & $38 \%$ & $48 \%$ & $100 \%$ \\
\hline
\end{tabular}

Fonte: Dados da pesquisa

As questões relacionadas ao perfil sócio-demográfico e a 'capacidade de planejamento' foram submetidas à análise bivariada na Tabela 6 com a finalidade de perceber o comportamento das mesmas.

Tabela 06: Comportamento das questões sócio-demográficas em relação à capacidade de planejamento.

\begin{tabular}{|c|c|c|c|c|c|c|c|}
\hline & \multirow[b]{2}{*}{ Descrição } & \multicolumn{5}{|c|}{ Não consigo fazer nada sem um planejamento bem detalhado } & \multirow[b]{2}{*}{ Total } \\
\hline & & $\begin{array}{c}\text { Discordo to- } \\
\text { talmente }\end{array}$ & Discordo & Neutro & Concordo & $\begin{array}{l}\text { Concordo To- } \\
\text { talmente }\end{array}$ & \\
\hline \multirow{2}{*}{ Sexo } & Masculino & $0 \%$ & $6 \%$ & $8 \%$ & $29 \%$ & $2 \%$ & $45 \%$ \\
\hline & Feminino & $2 \%$ & $8 \%$ & $16 \%$ & $20 \%$ & $8 \%$ & $55 \%$ \\
\hline & Total & $2 \%$ & $14 \%$ & $24 \%$ & $49 \%$ & $10 \%$ & $100 \%$ \\
\hline \multirow{4}{*}{ Idade } & Menos de 20 anos & $0 \%$ & $4 \%$ & $0 \%$ & $2 \%$ & $0 \%$ & $6 \%$ \\
\hline & De 20 a 23 anos & $0 \%$ & $6 \%$ & $14 \%$ & $22 \%$ & $4 \%$ & $47 \%$ \\
\hline & De 24 a 27 anos & $2 \%$ & $4 \%$ & $6 \%$ & $22 \%$ & $6 \%$ & $41 \%$ \\
\hline & De 27 a 30 anos & $0 \%$ & $0 \%$ & $4 \%$ & $2 \%$ & $0 \%$ & $6 \%$ \\
\hline & Total & $2 \%$ & $14 \%$ & $24 \%$ & $49 \%$ & $10 \%$ & $100 \%$ \\
\hline \multirow{5}{*}{ Pais } & Angola & $0 \%$ & $0 \%$ & $0 \%$ & $2 \%$ & $0 \%$ & $2 \%$ \\
\hline & Cabo-Verde & $2 \%$ & $8 \%$ & $14 \%$ & $16 \%$ & $0 \%$ & $41 \%$ \\
\hline & Guiné-Bissau & $0 \%$ & $4 \%$ & $8 \%$ & $29 \%$ & $10 \%$ & $51 \%$ \\
\hline & Moçambique & $0 \%$ & $0 \%$ & $2 \%$ & $0 \%$ & $0 \%$ & $2 \%$ \\
\hline & $\begin{array}{l}\text { São Tomé e Prín- } \\
\text { cipe }\end{array}$ & $0 \%$ & $2 \%$ & $0 \%$ & $2 \%$ & $0 \%$ & $4 \%$ \\
\hline & Total & $2 \%$ & $14 \%$ & $24 \%$ & $49 \%$ & $10 \%$ & $100 \%$ \\
\hline
\end{tabular}

Fonte: Dados da pesquisa

Os dados indicam que apesar de registrarem $55 \%$ da resposta total, as pessoas do sexo feminino foram as que apresentaram resultados mais preocupantes, tendo em vista que $26 \%$ delas acreditam que são capazes de fazer algo sem um planejamento. Em relação ao sexo masculino, $31 \%$ concordaram parcialmente ou totalmente com a assertiva: Não consigo fazer nada sem um planejamento bem detalhado.

O cruzamento da variável idade com a assertiva anterior apresentou um resultado interessante relativamente à con- cordância dos entrevistados. Assim, tem-se uma igualdade de respostas $(22 \%)$ dos pesquisados na faixa de 20 a 23 anos e os de 24 a 27 anos, sendo que esta última categoria se destaca com $28 \%$ de concordância parcial ou total contra $26 \%$ da primeira categoria (de 20 a 23 anos).

Em relação aos países que se fizeram presentes neste estudo, através dos seus estudantes, Guiné-Bissau se destaca com 39\%, seguido de Cabo-Verde com $16 \%$. Nessa óptica os dados permitem inferir que os estudantes provenientes de Gui- 
né-Bissau não conseguem realizar nada sem antes ter realizado um planejamento.

Em suma, após a análise dos dados apresentados na tabela abaixo, constatou-se que os homens na faixa de 24 a 27 anos, nacionais da Guiné-Bissau foram os que apresentaram respostas mais satisfatórias demonstrando, dessa forma, que o planejamento é fundamental nas suas vidas.

Como foi abordado anteriormente, o propósito dessa seção foi de analisar o comportamento, através da análise bivariada, das variáveis relacionadas ao perfil empreendedor e as questões sócio-demográficas.

Na próxima seção serão apresentadas as principais considerações favorecidas pela revisão da literatura e análise dos dados coletados.

\section{Considerações finais}

Empreendedorismo, em quando campo de estudo, tem suscitados interesses de estudiosos, governantes e sociedade civil de um modo geral. O despertar para o empreendedorismo se deve à importância do mesmo para o desenvolvimento econômicos dos países, em função disso, como já visto anteriormente, não se tem um consenso sobre os conceitos de empreendedorismo e empreendedor.

Vale ressaltar que, um dos pontos analisados quando se discute empreendedorismo, trata-se da visão sistêmica das pessoas envolvidas em novos negócios ou com perfil intraempreendedor, ou seja, aquele que busca desempenhar sempre suas funções da maneira adequada e procurando alternativas inovadoras nas suas atribuições, tendo retorno pessoal e para a organização na qual está inserido. Assim, os estudantes aqui pesquisados, apresentam propensão ao empreendedorismo, o que poderá resultar em ganhos para os seus países de origens, que necessitam de pessoas empreendedoras e com visão sistêmica e critica da iniciativa privada e o setor público. Vale lembrar aqui que, como é de conhecimento geral, os países africanos posicionam-se na base da pirâmide, já que são marcados por processos de independência e de consolidação política tardios.

Portanto, a finalidade desta investigação foi de analisar a propensão dos estudantes africanos, da Universidade $\mathrm{Fe}$ deral de Alagoas, ao empreendedorismo. Assim, a questão de pesquisa, os estudantes africanos da Universidade Federal de Alagoas, participantes do Programa Estudante Convenio de Graduação (PEC-G), têm propensão ao empreendedorismo, foi respondida bem como o objetivo geral do estudo foi alcançado.

O teste de hipótese sugeriu a rejeição da hipótese nula, dessa forma, conclui-se que o público alvo tem propensão ao empreendedorismo.

A análise univariada possibilitou responder ao primeiro objetivo específico (traçar o perfil do público alvo), ou seja, o mapeamento do perfil dos entrevistados. Nesse âmbito, percebe-se que a maioria dos entrevistados é do sexo feminino, na faixa etária de 20 a 23 anos, provenientes da Guiné-Bissau ligados aos cursos da área de Ciências Sociais Aplicadas, com características empreendedoras apresentadas na sequência desta discussão.

Em relação ao segundo objetivo específico (analisar as características empreendedoras dos pesquisados), o estudo, apesar do teste de hipótese apontar para a propensão ao empreendedorismo, algumas respostas, dos entrevistados, relacionadas à característica empreendedora (Liderança, Cooperação, Planejamento) se mostraram preocupantes. Por isso sugere-se, tendo em vista que a disciplina de empreendedorismo não é ofertado para alguns cursos na UFAL, a criação de outros cursos de extensão para esse público e maior foco na disseminação e publicização da "Semana de Empreendedorismo" desenvolvida anualmente pela Universidade Federal de Alagoas, aberto para todos os estudantes da IES e seu entorno regional. 
Os resultados apresentados demonstram o potencial dos estudantes em relação à busca de informação, são persistentes e enfatizam o desejo de liderar, com cooperação e planejamento, entretanto, como verificado nos resultados, alguns se sentem inseguros sobre certas atitudes ou decisões que devem ser tomadas. Diante disso, dois pontos a serem considerados: a cultura de origem dos estudantes e os cursos que fazem na UFAL.

Assim, o primeiro ponto, por tratar de países de origens, onde o Estado é o maior empregador, torna-se difícil tomar decisões de abrir seu próprio negócio, o que explica o fato da maioria dos empreendimentos existentes nesses países serem de propriedade de estrangeiros. Esta condição aumenta a responsabilidade destes estudantes ao retornarem aos seus países de origens, para implementarem ações que despertem atitudes empreendedoras em potenciais empreendedores daqueles países.

Nesse âmbito, os alunos ora pesquisados, podem aproveitar os conhecimentos e as experiências dos empreendedores brasileiros, tendo em vista que o Brasil é considerado um país empreendedor, apesar de algumas falhas ainda existentes, para engendrar o processo de mudança cultural, e lembrando aqui, sabido por todos, um trabalho de muito longo prazo.

O segundo ponto, no entanto, seria de fácil efetivação, visto que poderia ser solicitado a UFAL e outras instituições de ensino brasileiras a oferta de disciplinas ligadas Empreendedorismo, a Criatividade, a Liderança, entre outras nas matrizes curriculares dos cursos oferecidos, independente da área, e assim, provocar mudanças no pensar dos estudantes de intercâmbio, especialmente aos estudantes do Programa Estudante Convênio de Graduação - PEC$\mathrm{G}$, em razão de mudança de cultura e anseios dos egressos formados pela UFAL ao retorno aos seus países com conhecimento elevado e capacidade empreendedora aguçada. Vale ressaltar que, o aprendizado também será para os estudantes brasileiros, abrindo-se portas de cooperação entre os países, onde as partes terão conhecimentos de suas necessidades e potencialidades.

Este estudo propõe além de demonstrar a propensão dos estudantes africanos ao empreendedorismo, tenta provocar uma reflexão de mudança cultural, considerado um projeto de longo prazo. Assim, em função das limitações relacionadas ao tamanho da amostra, recomenda-se a realização de novas pesquisas abrangendo o universo dos estudantes convênios de graduação oriundos dos países africanos, pois deste modo, poderá desenvolver ações para melhoria de disciplinas ofertadas na IES, bem como trocar experiências entre países de origens dos estudantes.

\section{Referências}

DEGEN, R. J. O empreendedor: fundamento das iniciativas empresarial, São Paulo: Mcgraw-Hill, 1989.

DOLABELA, F. O segredo de Luísa. São Paulo: Cultura Editores Associados, 1999.

DOLABELA, F. Oficina do empreendedor. São Paulo: Cultura Editores Associados, 1999.

DOLABELA, F. Pedagogia empreendedora. São Paulo: Editora de Cultura, 2003.

DORNELAS, J. C. A. Empreendedorismo: transformando idéias em negócios. Rio de Janeiro: Campus, 2001.

FEUERSCHÜTTE, S. G.; GODOI, C. K. Competências empreendedoras: um estudo historiográfico no setor hoteleiro. In: XXXI EnANPAD - ENCONTRO NACIONAL DOS PROGRAMAS DE PÓSGRADUAÇÃO EM ADMINISTRAÇÃO. Anais eletrônicos. Rio de Janeiro: ANPAD, 2007.

FILION. L. J.; DOLABELA, F. (Orgs.). Boa idéia! e agora: plano de negócio, o caminho seguro para criar e gerenciar sua empresa. São Paulo: Cultura Editores Associados, 2000. 
GERBER, M. E. O mito do empreendedor: como fazer de seu empreendimento um negócio bem sucedido. São Paulo: Saraiva, 1996.

GIMENEZ, F. A. P.; JÚNIOR, E. I. Potencial empreendedor: um instrumento de mensuração. In: XXII - SEGeT - SIMPÓSIO DE GESTÃO DA INOVAÇÃO TECNOLÓGICA. Anais eletrônicos. Salvador, 2002.

GOMES, C. C. C.; OLIVEIRA, K. R. S. Pedagogia empreendedora: um estudo de caso das práticas metodológicas desenvolvidas na disciplina "empreendedorismo" do curso de administração da UFAL. Trabalho de Conclusão de Curso de Administração. Universidade Federal de Alagoas. Maceió, 2008.

KRISTIANSEN, S.; INDARTI, N. Entrepreneurial intention among Indonesia and Norwegian students. Journal of Enterprising Culture. v. 12, n. 1, p. 55-78, march, 2004.

LIMA, M. O.; SANTOS, S. A.; DANTAS, A. B. Propensão ao empreendedorismo dos Alunos do Ensino Fundamental: um Estudo Comparativo com alunos de $7^{\mathrm{a}}$ e $8^{\mathrm{a}}$ séries, entre Instituições de Ensino Municipais e Privadas de Maceió. In: XXX EnANPAD - ENCONTRO NACIONAL DOS PROGRAMAS DE PÓSGRADUAÇÃO EM ADMINISTRAÇÃO. Anais eletrônicos. Salvador: ANPAD, 2006.

LISBOA, T. C. O ser e o desprender humano. In: KUAZAQUI, E. (Org.). Liderança e criatividade em negócios. São Paulo: Thomson Learning, 2006.

LOPES, R. M. A. Short term results evaluation of competence based training for entrepreneurs: Empretec Program. São Paulo: USP, 1999.

MALHOTRA, N. K. Pesquisa de marketing: uma orientação aplicada. 4. ed. Porto Alegre: Bookman, 2006.
MALHOTRA, N. K.; ROCHA, I.; LAUDISIO, M. C.; ALTHEMAN, É.; BORGES, F. M. Introdução à pesquisa de marketing. São Paulo: Prentice Hall, 2005.

NASCIMENTO JR., O. R. Potencial empreendedor do empresário alagoano: proposição e validação de um instrumento. Dissertação de Mestrado em Administração. Universidade Federal de Alagoas. Maceió, 2005.

NASCIMENTO, T. C.; BARROS, A. D.; MILITO, C. M.; LIMA, E. O.; SANTOS, P. C. F. Potencial Empreendedor em Alunos de Ensino Superior: testando a metodologia de Kristiansen e Indarti em Alagoas. In: XXXI EnANPAD - ENCONTRO NACIONAL DOS PROGRAMAS DE PÓS-GRADUAÇÃO EM ADMINISTRAÇÃO. Anais eletrônicos. Rio de Janeiro: ANPAD, 2007.

NUEVO, P. Empreendiendo el arte de crear empresas y sus artistas. Ediciones Deusto Bilbao, 2001.

OLIVEIRA, S. L. Tratado de metodologia científica: projetos de pesquisas, TGI, TCC, monografias, dissertações e teses. São Paulo: Pioneira Thomson Learning, 2004.

PAIVA JR., F. G.; LEÃO, A. L. M.; MELLO, S. C. B. Competências empreendedoras em comportamentos de dirigentes de êxito socialmente reconhecido. In: XXVII EnANPAD - ENCONTRO NACIONAL DOS PROGRAMAS DE PÓSGRADUAÇÃO EM ADMINISTRAÇÃO. Anais eletrônicos. Atibaia: ANPAD, 2003.

PEREIRA, C. E. C.; COSTA, A. C. S. Potencial empreendedor dos alunos do ensino médio em escolas públicas e privadas de Maceió. In: XXVI ENEGEP - ENCONTRO NACIONAL DE ENGENHARIA DE PRODUÇÃO. Anais eletrônicos. Fortaleza, 2006. 
PHELAN, S. E.; ALDER, G. S. An experimental study of entrepreneurial exploitation. Disponível em: http://faculty.unlv.edu/phelan/Research/Ph elanAl-

der_An\%20experimental\%20study\%20of \%20entrepreneurial\%20exploitation_MgtS ci.pdf. Acesso em: 10 ago. 2012.

SAIKOVITCH, V. L. Empreendedorismo em serviços. In: KUAZAQUI, E. (Org.). Liderança e criatividade em negócios. São Paulo: Thomson Learning, 2006.

SANTOS, P. C. F. Uma escala para identificar potencial empreendedor. Tese Doutorado em Engenharia de Produção. Universidade Federal de Santa Catarina. Florianópolis - SC, 2008.

SANTOS, S. A. Diferenças da intenção empreendedora entre alunos do ensino presencial e a distância matriculados no curso de administração da UFAL. Trabalho de Conclusão de Curso de Administração. Universidade Federal de Alagoas. Maceió, 2008.

SCHMITT-RODERMUND, E. Pathways to successful entrepreneurship: parenting, personality, early entrepreneurial competence, and interests. Journal of Vocational Behavior, v. 65, p. 498-518, 2004.

SHUMPETER, J. A. Teoria do desenvolvimento econômico. Rio de Janeiro: Fundo de Cultura, 1959.

SMITH-HUNTER, A.; KAPP, J.; YONKERS, V. A psychological model of entrepreneurial behavior. Journal of the Academy of Business and Economics, v. 2, n. 2, p. 180-192, 2003.

TAVARES, T. S.; LIMA, J. B. Empreendedorismo, empreendedores e ação empreendedora. In: XXVIII EnANPAD - ENCONTRO NACIONAL DOS PROGRAMAS DE PÓS-GRADUAÇÃO EM ADMINISTRAÇÃO. Anais eletrônicos. Curitiba: ANPAD, 2004.
TRIVIÑOS, A. N. S. Introdução à pesquisa em ciências sociais: a pesquisa qualitativa em educação. São Paulo: Atlas, 2006. 